\title{
Verzeichnis der Illustrationen.
}

${ }_{n}$ Das grofse Staatsoiegel" ${ }_{n}$ Glänzende Aufzüge" ${ }^{*}$. . . 1 ${ }_{n}$ Kehrichtshor ${ }^{u}$ ${ }_{n}$ Ein trocknes Stückchen Brot ${ }^{\mu}$. 5 ${ }_{n}$ Des Priesters alte Bücher" . . 6 ${ }_{n}$ Er sah die arme Anna Askew" 8 ${ }_{n}$ Erwachsene Leute wendeten sich an Tom ${ }^{4}$ nAn den Fenstern der Garküchen" ${ }^{\text {A }}$ ${ }_{n}$ Nach Temple Bar" . . . . . 11 ${ }_{n} \mathrm{Lafs}$ ihn ein" . . . . . . . 14 ${ }_{n}$ Wie alt sind die Beiden ?" . . 16 ${ }_{n}$ Ziehe dies Prachtgewand an" . 18 ${ }_{n}$ Scher Dich fort!" . . . . . 20 ${ }_{n}$ Hierher Packan!" . . . . . 25 ${ }_{n}$ Ein grofser betrunkener Kerl ${ }^{4}$. 27 ${ }_{n} \mathrm{Er}$ zog den Degen" . . . . 29 ${ }_{n}$ Bebend öffnete er die Thür" . 30 "O erbarmet Euch meiner" . . 31 ${ }_{n}$ Der Prinz kommt!" . . . . 33 ${ }_{n} \mathrm{Du}$, der König! ${ }^{\natural}$. . . . . . 34

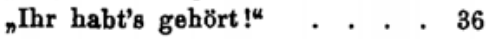
${ }_{n}$ Der Arzt verneigte sich ${ }^{*}$. . . 37 ${ }_{n}$ Der König sank auf sein Ruhebett" . "Soll dieser Mensch ewig leben?" "Besteht nicht darauf, mein Prinz" ${ }_{n}$ Lord St. John verbeugte sich" ${ }_{n}$ Lord Hertford und die Prinzessinnen ${ }^{4}$. . . . . . . . 46 ${ }_{n} \mathrm{Sie}$ verneigte $\operatorname{sich}^{4}$. . . . . 49
${ }_{n}$ Reichte ihm den Becher auf einem goldenen Teller" . . 50 ${ }_{n}$ Sie sannen eine Weile nach" . 52 "Schweigt, mein Lord, das ist Hochverrath" . . . . . . 53 ${ }_{n}$ Endlich stand er wieder auf ${ }^{4}$. 54 ${ }_{n}$ Befestigte das Mundtuch" . . 57 ${ }_{n}$ Tom griff mit den Fingern in die Teller ${ }^{4}$. . . . . . . 59 ${ }_{n}$ Tom trank einen Schluck" . . 60 "Tom legte die Beinschienen an" 61 ${ }_{n}$ Die Diener lehnten ihn in die Kissen zurück" * . . . . 64 ${ }_{n}$ Eine Abtheilung von Hellebardieren ${ }^{\mu}$. . . . . . . . 68 nTom Canty wurde jetzt sichtbar ${ }^{4} \quad 70$ ${ }_{n}$ Eine dunkle Gestalt sank zu. Boden" . . . . . . . . 73 ${ }$ Wer bist Du ?" . . . . . . 75 "Ein schwerer Schlag von Canty's wuchtiger Faust" . . . . 77 ${ }_{n}$ Sie beugte sich über ihn ${ }^{4}$. . 79 ${ }_{n}$ Der Prinz richtete sich auf" 81 "Tom Canty hatte den Prinzen am Arm gepackt" . . . . 82 ${ }_{n}$ Er verlor keine Zeit ${ }^{\mu}$. . . . 84 ${ }_{n} \mathrm{Zu}$ einem reichgeschmückten Baldachin" . . . . . . 88

${ }_{n}$ Die Getroffenen fielen rechts und links" . . . . . . . . 91 ${ }_{n}$ Lang lebe der König ${ }^{\star}$. . . . 93 
" $\mathrm{Er}$ und Miles Hendon drängten sich $^{\prime}$. . . . . . . .

nAnschauungsunterricht in der englischen Geschichte" . nTom Canty entfernte sich" . ${ }_{n}$ Strich ihm die wirren Locken aus der Stirn". "nitte giefse das Wasser ein " ${ }_{n}$ Erzähle mir Deine Lebensgeschichte" . . . . . . .

${ }_{n}$ Dir ist abschenlich mitgespielt worden" . . . . . . .

${ }_{n}$ Er beugte das Knie". . . . nStehe als Ritter auf, Sir Miles Hendon!"

„Er schlief ein" .

nSo weit ist das Wams ganz gut" "Erkläre mir das!"

"Hendon eilte ihm nach" ${ }_{n}$ Ich bin Deines Befehls gewärtig ${ }^{4}$ ${ }_{n}$ Der erste Kammerherr hatte das Kleidungsstück in Empfang genommen" . . . "Ein Staatssekretär verlas eine Verfügung" .

"Der Knabe erhob sich".

"Ich bekomme immer die Schläge"

"Tom war wieder rathlos" .

nTom war an ein Fenster getreten"

nTom betrachtete die Gefangenen aufmerksam"

nSetzt den Gefangenen in Freiheit"

nWas haben sie gethan ?" .

${ }_{n}$ Einige Grauköpfe in der Versammlung nickten ${ }^{*}$

„Ein Edelmann erscheint mit einem Stabe

„Der Kanzler, welcher zwischen zwei Rittern geht" . .
Seite
"Dank, Dank, mein gutes Volk ।" ${ }_{n} \mathrm{Er}$ entfernte sich" . ${ }$ Der Kerl folgte ihnen" . . . 158 ${ }$ Er ergriff ein Holzscheit" ${ }^{4}$. 160 ${ }_{n}$ Dort legte er sich nieder ${ }^{4}$. . 161 ${ }_{n}$ Ein unheimlicher und widerwärtiger Anblick ${ }^{4}$. . . 162 ${ }_{n}$ Dann stimmten die Beiden ein Schelmenlied an ${ }^{4}$. . . . 165 ${ }_{n}$ Zum Feuertode verurtheilt" ${ }^{*} 166$ „An die Rückseite eines Karrens gebunden" . . . . . , 167 "Das soll nicht geschehen" . 169 "Schlug Hobbs mit der Faust" 171 "Statt des Thrones auf einem Fasse" . . . . . . . 172 „Die Bande machte sich auf den Weg". . . . . . . . 175 "Sie warfen mit Knochen und Kohlstrünken" . . . . . 177 „Er wand sich im Staube“ . . 179 ${ }_{n}$ Der König entfloh" . . . . 180 ${ }_{n}$ Noch wankte er vorwarts" . 182 „Das sich wie ein warmes Seil anfühlte* . . . . . . . 184 ${ }_{n}$ Schmiegte sich an den Rücken des Kalbes" . . . . . 186 ${ }$ Wer bist Du, Junge?" . . . 188 "Die Mutter der Madchen empfing ibn freundlich" . . 190 „Die Hausfrau kehrte glücklicherweise zurù̀ck “ . . . 192 ${ }_{n}$ Ein Schlachtmesser zu schleifen" 194 ${ }$ Er wartete nicht erst" . . . 197 ${ }_{n}$ Der König trat ein" . . . . 199 nIch will Dir ein Geheimnis anvertrauen" . . . . . . 201 „Er plauderte so schlicht und freundlich" . . . . . . 203 ${ }_{n}$ Es wird schon schärfer" . . 205 nIm nächsten Augenblick waren sie gebunden ${ }^{*}$. . . . 206 
Seite

"Sank auf die Kniee ${ }^{\alpha}$. . . 210

${ }_{n}$ Nun hörte man stampfen, trampeln" . . . . . . . . 213

"Der geknebelte kleine König" ${ }_{n}$ Die Aussichten für Hugo waren nicht gut"

${ }_{n}$ Hugo band das Pflaster fest" ${ }_{n}$ Warte hier bis ich wiederkomme" . . . . . . . "Der König eilte auf seinen Befreier zu" . . . . . ${ }$ Nichts da, guter Freund ! "Sie sprang entsetzt auf" . „Das Schwein kann Dich den Hals kosten " . . . . . 234 ${ }_{n}$ Haltet mich!" . . . . . . 236 "Sie ritten langsam" . . . . 240 „Dort ist das Dorf" . . . . 242 "Umarme mich, Hugh" . . . 244 ${ }_{n}$ Hugh hob abweisend die Hand 4245 ${ }_{n}$ Eine schöne kostbar gekleidete Frau" . . . . . . . . 248 "Nun durchschaue ich Dich !" 249 nGehorche mir und habe keine Furcht" . . . . . . . 252 ${ }_{n}$ Bin ich Miles Hendon ?" . . 255 nMan legte die Freunde an Ketten" die Freunde an "Der alte Mann trat näher" . 260 "Durch leise geflüsterte Worte" nDes Königs? Welches Königs ?" "Die beiden Frauen an hölzerne Pfähle gekettet" . . . . 266

„Von den Henkersknechten zurückgerissen" . . . . . 268 „Der König war empört" . . 270
Seite "Schämt Euch l" . . . . . . 274 nWährend die Peitsche auf ihn herniedersauste" . . . . 276 "Sir Hugh wendete sein Pferd" 278 nEr stieg auf und ritt mit dem Könige" . . . . . . . 280 „Dichtgedrängt voll jubelnder, schreiender,johlenderLeute" 282 "Wenn sie seine Hand külsten ${ }^{4} 284$ ${ }_{n}$ Befahl ihr, sich in ihre Gemächer zurückzuziehen" ${ }^{4}$. 285 "Der Aufbruch nach dem Tower" 289 "Willkommen!" . . . . . . 291 "Ein Gnadengeschenk!" . . . 292 "Stand sie an seiner Seite". . 295 "Mein Lehensherr, jetzt ist nicht die Zeit Träumen nachzuhängen " . . . . . . 297 „Es war meine Mutter!“ . . . 298 „Ein zweiter trägt die lange Schleppe ${ }^{u}$. . . . . . 300 ${ }_{n}$ Tom Canty erschien" . . . 303 "Sank vor ihm auf die Kniee" 305 ${ }_{n}$ Das grofse Siegel - bringt es her!" . . . . . . . 308 ${ }_{n}$ Sire, das Siegel ist nicht dort !" 310 "Besinne Dich, mein Konnig !" . 311 ${ }_{n}$ Lang lebe der rechtmäfsige König!" . . . . . . . 314

nUm Nüsse damit zu knacken !" 315 ${ }_{n}$ Dann schlief er ein ${ }^{4}$. . . . 319 ${ }_{n}$ Noch ein Kronprätendent!" . 322 ${ }_{n}$ Es ist sein gutes Rechtl ${ }^{4}$. . 325

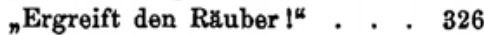
"Tom erhob sich und küfste die Hand $^{\mu}$. . . . . . . . 327 

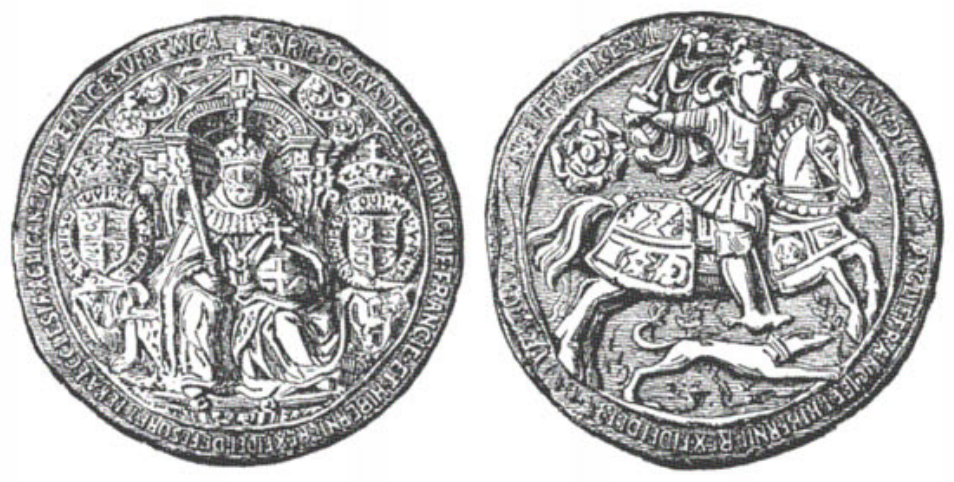

$$
564 \text { rizp }
$$


Die Art der Gnade weifs von keinem Zwang,

Sie träufelt wie des Himmels milder Regen,

Zur Erde unter ihr; zwiefach gesegnet :

Sie segnet, den der giebt, und den der nimmt;

Am Mächtigsten in Măcht'gen, zieret sie

Den Fürsten auf dem Thron mehr wie die Krone.

Der Kaufmann von Venedig. 
